\title{
An evaluation of methods for behavioral investigations of teleost audition*
}

\author{
ARTHUR N. POPPER, ALBERT T. H. CHAN \\ and NANCY L. CLARKE \\ Department of Zoology and Laboratory of Sensory Sciences \\ University of Hawaii, Honolulu, Hawaii 96822
}

Auditory thresholds have been determined for the goldfish by six groups of workers and the data in the experiments varied by as much as 20-30 dB. In order to isolate the basis for this variability, auditory thresholds were determined using conditioned suppression of respiration and method of limits. These thresholds were very similar to those obtained with avoidance conditioning and a tracking method for threshold determination. Acoustic procedures were kept constant in the two series of experiments, and it appears that wide variation in auditory thresholds for goldfish shown in different experiments is due to acoustic conditions in the experiments.

Behavioral investigations of audition in teleost fishes have demonstrated considerable variation in the range of frequencies and minimum sound levels detectable by different species (see review by Popper \& Fay, 1973). However, while the data indicate extensive variation in auditory sensitivity between different species, it is not possible to tell whether this is due to differences in experimental techniques or to variation in auditory sensitivity. The problem is highlighted by the fact that auditory thresholds have been determined for the goldfish (Carassius auratus) by six different groups of workers; the thresholds vary by as much as $20-30 \mathrm{~dB}$ between experiments (see Fig. 1). Consequently, it is not possible to validly compare interspecific auditory capabilities in fishes on any but the crudest levels. In order to make such comparisons, it is necessary to determine the methodological bases for the variation and to control or eliminate them from the experiments.

The effects of method on threshold determination have been explored by Dalton (1968) and Stebbins (1970) with monkeys. Dalton found that thresholds were up to $12 \mathrm{~dB}$ lower with conditioned suppression methods than with galvanic skin response. He found higher thresholds with evoked cortical responses. Stebbins (1970), using the methods of constant stimuli, limits, and tracking, found no significant differences in thresholds. Unfortunately, the experiments with monkeys provide no clue concerning the bases for variation in thresholds determined for the goldfish.

In each of the six experiments illustrated in Fig. 1, the workers used different behavioral, psychophysical, and

*This work was supported by Public Health Service Grants NS-09374 and NS-06890 from the National Institute of Neurological Diseases and Stroke. We would like to express thanks to $R$. R. Fay and $W$. T. Woodard for valuable discussions about the conditioned suppression technique. William $R$. Uttal and $H$. Popper kindly read and commented on the manuscript. acoustic methods for threshold determination. In only one case (Enger, 1966) was acoustic method changed and the others held constant. Enger found a significant difference in thresholds when the speakers were shifted from air to water; this could be taken to suggest that threshold variation is a function of acoustic situation. However, Enger also varied the distance between the speakers and fish. This additional manipulation prevents a positive conclusion that variation in acoustic condition is the primary explanation for the variation in the goldfish data.

In order to test the role of acoustic condition in threshold determination, an experiment was designed to test auditory thresholds while keeping acoustic conditions constant but varying behavioral methods and psychophysical techniques. Data were obtained using classical conditioning of suppression of respiration and method of limits.

\section{METHODS}

Experiments were performed with goldfish $40-100 \mathrm{~mm}$ in length. Animals were tested in acoustic chambers with air

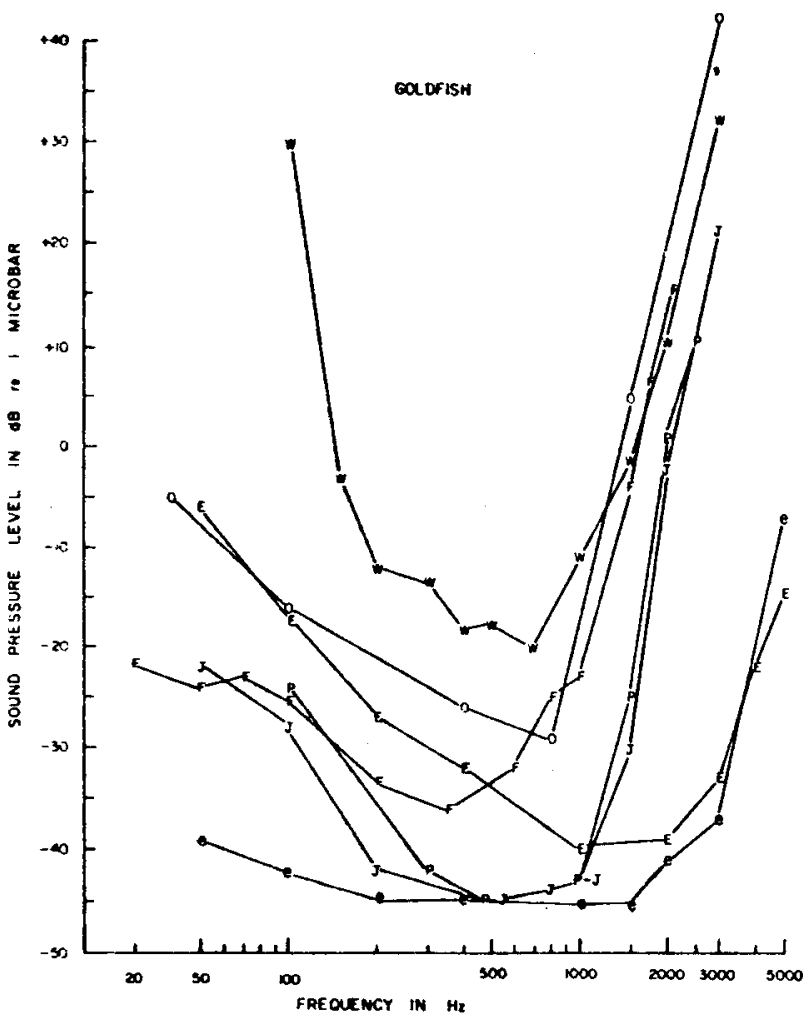

Fig. 1. Auditory thresholds for the goldfish (Carassius auratus) determined by a number of workers. $E$ and e-Enger, 1966; F-Fay, 1969; J-Jacobs \& Tavolga, 1967; O-Offutt, 1968; P-Popper, 1971; W-Weiss, 1966 (from Popper \& Fay, 1973). 


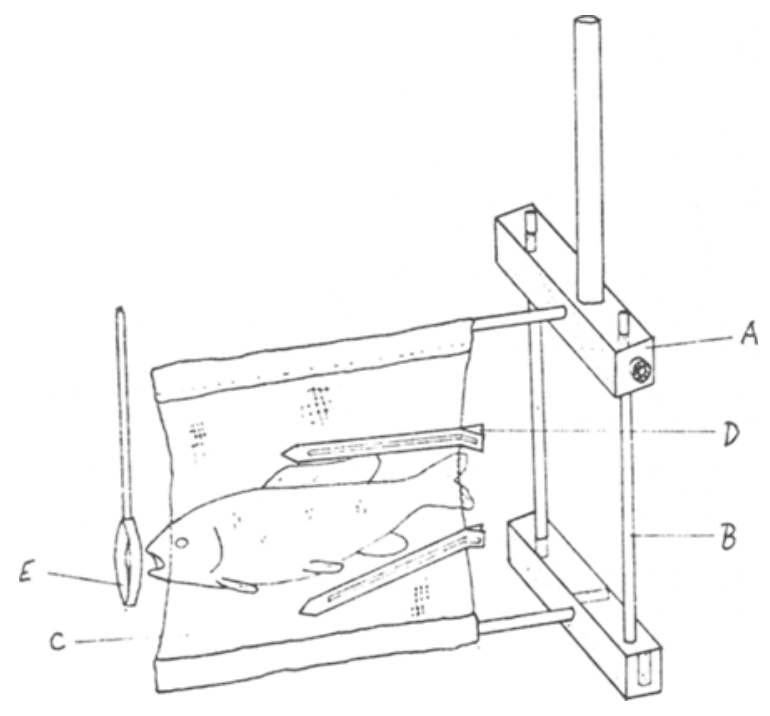

Fig. 2. Fish holder used for conditioned suppression. The outline of the fish is shown, but in the actual holder all but the mouth of the fish is covered with cheesecloth. The upper plastic bar (A) moves on metal bars (B) to slacken the cheesecloth bag (C) to permit putting the fish in the bag. Clips (D) are used to keep the fish from moving backwards. The front of the bag is sewn closed except for the mouth opening. Mouth movements during respiration push a paddle (E), which connects to a phonograph cartridge.

loudspeakers $10 \mathrm{~cm}$ from the center of Plexiglas test tanks. The fish were suspended in the center of the test tank in a cheesecloth bag held between metal bars attached to two pieces of Plexiglas (Fig. 2). The fish's mouth protruded through the front of the bag and, during respiration movements. pushed a paddle which was attached to and stimulated a phonograph cartridge. The output of the cartridge was filtered, preamplified, and recorded on a Brush 220 pen recorder. An automatic control system presented the sounds, controlled the pen recorder, and set sound levels for each trial through a step attenuator.

Prior to the beginning of each trial, the pen recorder was turned on for $10 \mathrm{sec}$ to obtain a pretest monitor of respiration rate and amplitude. The sound was presented for $5 \mathrm{sec}$ and was then followed by a single ac pulsed ( $40 \mathrm{msec}$ duration) shock through electrodes placed at either end of the test tank. The shock level (generally $8-10 \mathrm{~V}$ ac at the source) was set to elicit a short-term $(1-3 \mathrm{sec})$ inhibition of breathing after the shock.

Thresholds were determined with pure tones from 300 to $1,500 \mathrm{~Hz}$. The sound system was identical to that described earlier (Popper, 1971, 1972a, b). Sounds from an oscillator were turned on and off slowly ( 10 -msec rise-decay time) by an electronic switch (Grason-Stadler 829E) in order to eliminate acoustic transients associated with too rapid rise times. The signal was then bandpass filtered, to eliminate clicks produced by the electronic switch, attenuated, and amplified. Sound levels were calibrated in the center of the test tank by using a hydrophone, and ambient noise levels were measured to ensure that the sound spectrum level (noise energy per cycle) was sufficiently below threshold so as not to cause masking of the absolute threshold.

The method of limits was used for threshold determination; due to technical problems, we used a descending order. The sound levels initially presented were varied, but were always well above the thresholds obtained in any of the earlier experiments with goldfish. After each trial, the sound level was lowered in 5 -dB steps for seven or eight successive trials and then returned to the initial level for further runs. The number of trials for each run was sufficient to bracket the threshold of the animals during each series of trials. The threshold point was determined by comparison of the tespiration patterns during each trial with the pattern during the $i 0 \mathrm{sec}$ preceding the trial. Since there was considerable stability in the respiration amplitude and rate during the $10 \mathrm{sec}$ prior to the trials, it was possible to select an amplitude and rate change of $10 \%$ of the prepresentation level as the response criterion level. If either amplitude (as measured on the calibrated chart recorder) or rate of respiration (breaths per 5 -sec period) varied by more than $10 \%$, a positive response was scored for that trial.

In order to ensure that the animals were not responding to signal artifacts, blank trials were alternated with the test trials. During each blank trial, the procedure was the same, except that the oscillator was off. The animals showed no false responses during the blank trials.

\section{RESULTS AND DISCUSSION}

Data were ootained at $300,500,800,1,000$, and $1,500 \mathrm{~Hz}$. The thresholds are shown in Table 1 along with data obtained by Popper (1971) using the same acoustic system with avoidance conditioning and a tracking method for threshold determination. The thresholds do not differ significantly from the earlier data (Mann-Whitney $U$ test, $p>.05$ ), indicating that the different behavioral and psychophysical methods do not adversely alter auditory thresholds for fish. In addition, these findings suggest that the different behavioral and psychophysical methods used by different workers do not significantly alter the data and that the major reason for the considerable variation in thresholds obtained for the goldfish is probably due to acoustic conditions. Consequently, workers must find an acoustic procedure which is easy to duplicate in a variety of experiments. This is difficult at best, since the sound field in small tanks is highly complex and essentially impossible to measure or describe mathematically (Parvulescu, 1964, 1967). The exact stimulus impinging upon the animal is unknown and it may consist of pressure and/or velocity information. Since fish are likely to be sensitive to both forms of acoustic energy, possibly with different receptors (van Bergeijk, 1964; Harris \& van Bergeijk, 1962; Popper \& Fay, 1973; Tavolga, 1971; and many others), a more suitable sound field with known pressure and velocity fields, similar to that described by Cahn, Siler, \& Wodinsky (1969) would be more appropriate. The important point is that true comparative studies of teleost audition will not be possible unless researchers utilize the same acoustic conditions or until the precise

Table 1

Auditory Thresholds (dB re: $1 \mu$ bar) for the Goldfish Determined Using (A) Classical Conditioning and (B) Avoidance Conditioning (Popper, 1971)

\begin{tabular}{ccc}
\hline Frequency & \multicolumn{1}{c}{ A } & B \\
\hline $300 \mathrm{~Hz}$ & $-46.4( \pm 6.68) 7^{*}$ & $-42.5( \pm 5.57) \dagger$ \\
500 & $-48.3( \pm 3.20) 11$ & $-44.9( \pm 4.10)$ \\
800 & $-40.1( \pm 4.96) 23$ & - \\
1000 & $-41.9( \pm 6.06) 25$ & $-42.8( \pm 5.53)$ \\
1500 & $-23.6( \pm 5.80) 6$ & $-24.8( \pm 5.79)$ \\
\hline
\end{tabular}

*Vumber of determinations

$\dot{T}$ dB re: 1 phar \pm I SD 
sound field impinging upon the fish can be defined so that the sound field is replicable. Once the sound field is standardized, the results of the experiment described here indicate that difference in psychophysical or behavioral techniques should be of no consequence.

\section{REFERENCES}

Cahn, P. H., Siler, W., \& Wodinsky, J. Acoustico-lateralis system of fishes: Tests of pressure and particle-velocity sensitivity in gunts, Haemulon sciurus and Haemulon sciurus and Haemulon parrai. Journal of the Acoustical Society of America, 1969. 46. $1572-1578$

Dalton, L. W. Jr. Auditory sensitivity in the rhesus (Macacca mulatta) and white-throated capuchin (Cebus capuchinus) monkeys: A comparison of three techniques. Aeromedical Research Laboratory, Holloman Air Force Base, 1968. AD-681-135.

Enger, P. S. Acoustic thresholds in the goldfish and its relation to the sound distance. Comparative Biochemistry \& Physiology, 1966, 18, 859-868.

Fay, R. R. Behavioral audiogram for the goldfish. Journal of Auditory Research, 1966, 9, 112-121.

Harris, G, G., \& van Bergeijk, W. A. Evidence that the lateral line organ responds to near-field displacements of sound sources in water. Journal of the Acoustical Society of America, 1962 , 34, 1831-1841.

Jacobs, D. W., \& Tavolga, W. N. Acoustic intensity limens in the goldfish. Animal Behaviour, 1967, 15, 322-335.

Offutt, G. C. Auditory response in the goldfish. Joumal of auditory Research, $1968,8,391-400$.

Parvulescu, A. Problems of propagation and processing. In $\mathbf{W} . \mathbf{N}$. Tavolga (Ed.), Marine bio-acoustics. Oxford: Pergamon Press, 1964.
Parvulescu, A. Acoustics of small tanks. In W. N. Tavolga (Ed.), Marine bio-acoustics II. Oxford: Pergamon Press, 1967.

Popper, A. N. The effects of size on the auditory capacities of the goldfish. Journal of Auditory Research, 1971, 11, 239-247.

Popper, A. N. Auditory thresholds in the goldfish (Carassius auratus) as a function of signal duration. Journal of the Acoustical Society of America, 1972a, 52, 596-602.

Popper, A. N. Pure-tone auditory thresholds for the carp, Cyprinus carpio. Journal of the Acoustical Society of America, 1972b, 52, 1714-1717.

Popper, A. N., \& Fay, R. R, Sound detection and processing by teleost fishes: A critical review. Journal of the Acoustical Society of America, 1973,53, 1515-1529.

Stebbins, W C Studies of hearing and hearing loss in the monkey. In W. C. Stebbins (Ed.), Animal psychophysics. New York: Appleton-Century-Crofts, 1970.

Tavolea, W. N. Sound production and detection. In W. S. Hoar and D. Randell (Eds.), Fish physiology. Vol. V. New York: Academic Press, 1971.

van Bergejk, W. A. Directional and nondirectional hearing in fish. In $W, N$, Tavolga (Ed.), Marine bio-acoustics. Oxford: Pergamon Press, 1964.

Weiss, B. A. Auditory sensitivity in the goldfish. Journal of Auditory Research, 1966, 6, 321-335.

(Received for publication July 11, 1973; revision received August 12, 1973.) 